Carlos Richet

\title{
El lenguaje y la inteligencia
}

AS relaciones del lenguaje con la inteligencia! He aqui un problema hace largo tiempo discutido, y por los más grandes filósofos, desde Platón. en el Crafilo. hasta Condillac, quien expuso ideas ingeniosas, hipotéticas y profundas sobre esta ardua cuestión. De tal suerte, ya parece excesivo ocuparse en ella.

No obstante, me parece que un psicólogo puede incurrir en la audacia de volver a considerarla desde un punto de visfa algo novedoso, y tralar de probar. por una parte. que la inteligencia, en su desarrollo, tiene necesidad de un lenguaje. y. por otra, que el lenguaje. en retribución. ha desarrollado considerablemente la inteligencia.

Me atrevo a esperar que se han de considerar estas dos proposiciones, expuestas aqui brevemente. con sus múltiples deducciones, como muy verosímiles, y consecuentemente, no merecedoras de ser reputadas paradojales.

Lo que es encialmente distingue al hombre del animal es el que éste carezca de lenguaje. Ciertamente, el animal, por diversas entonaciones, indica los varios sentimientos qne lo agitan. Sus deseos, sus impulsos, sus repulsiones, se traducen claramente en sonidos distintos. Pero esto no es la palabra, evidentemente. 
-Dime. ¿cuál es tu suerte?. pregunta Mercurio a Sosias. Ser hombre y hablar, responde Sosias. con una concisión maravillosa. $\mathrm{Y}$ es hombre, porque habla.

Por medio de gritos y sonidos, los animales más inteligentes pueden hacerse comprender. No se requiere estar muy experimentado para reconocer, según sus diversas sonoridades vocales, los sentimientos de un perro: dolor, alegría, cólera, temor. hambre, deseo de pasear, pesar al ver alejarse a su amo, persecusión de una presa. (aún con conocimiento de tal o cual caza). Todos estos movimientos de su alma animal se traducen en el exterior por ladridos, aullidos. gruñidos, gemidos, cuyas modalidades, harto diferentes, son, a no dudarlo, comprendidas por todos los animales de su especie, y aún por otros. Sin embargo. estos ruidos de la laringe no constituyen de manera alguna un lenguaje articulado. Revelan sentimientos simples, sufrimientos o alegrias: pero no hay en esto ninguna sintesis, ningún análisis. El perro es como el niño que aun no habla y que, no obstante. puede comunicar a los que la rodean alguna noción de sus apetitos o de sus sentimientos. También el perro puede hacerse comprender muy bien mediante su voz. Pero su voz no revela sino emociones. Los sonidos que emite son reflejos psíquicos y nada más.

Hay un abismo entre la sensación y el pensamiento. Se puede concebir un ser animado de sentimientos afectivos o repulsivos muy luertes, capaz de ligar sentimientos presentes a sensaciones pasadas, como por ejemplo. en el perro, el temor y el látigo. el hambre y la comida, la caza y el fusil. Estas asociaciones de imágenes no son sino embriones de pensamiento. Puesto que lo que distingue el pensamiento no es la asociación simple de dos imágenes, es decir, la memoria, sino la abstracción. la generalización, y para emplear un término algo técnico. el silogismo.

Sin lenguaje. no hay razonamiento. En el ser que no habla. todo es emoción, y emoción muy simple. Tal vez algunos rudimentos de pensamiento. obscuro. indeciso. nebuloso. flotan en las profundidades de su conciencia incierta; pero la sensación presente lo invade por entero. Sólo el lenguaje permite a la in- 
teligencia el concepto de ideas generales, necesario al verdadero pensamiento.

Deberia hablar aqui del origen del lenguaje. Pero como respecto de todos los origenes, en éste quedamos reducidos a vanas hipótesis.

¿Cómo podemos explicarnos el que tonalidades diferentes. después de muchos. laboriosos e infructuosos tanteos, hayan logrado por fin expresar objetos diferentes (sustantivos): que en seguida otras tonalidades hayan servido para traducir acciones diferentes (verbos); y que por fin se haya establecido por un sonido un enlace entre el verbo y el sustantivo? ¿Por qué inflecciones vocales nuevas ha podido indicar su yo el animal?... Pero no deseo ir más lejos: pues se trata de consideraciones sin ningún sostén cientifico, sin ninguna verosimilitud.

Lo que es verdad es que los salvajes más atrasados tienen ya un lenguaje; lenguaje informe, es verdad, cambianle. complicado, inadecuado a las cosas y los actos. Pero ya es un lenguaje. ¡Qué formidable esfuerzo intelectual ha necesitado el hombre primitivo para pasar de los gritos inarticulados de dolor o de hambre a esta lengua rudimentaria!

Ch. Darwin. que estudió sumariamente el origen del lenguaje. no da sino indicaciones extremadamente imperfectas. Pero no es por su culpa. puesto que no habia nada más que decir. Todo lo que me parece digno de recordarse de estas breves y medianas páginas que consagra a este estudio. es que los pájaros y los mamileros enseñan a su prole ciertos sonidos, ciertos gritos particulares, de suerte que. según la apariencia, las entonaciones que emiten los adultos no son siempre instintivas. sino adquiridas por una especie de verdadera educación.

Esta cuestión de la educación del lenguaje habia ocupado ya a los antiguos. Heródoto refiere. a este propósito. el caso poco verosimil de dos niños muy jóvenes trasladados a la cima de una torre y alimentados por las águilas, que no oyeron ja- 
más una palabra humana. Al cabo de algunos años. cuando estos niños crecieron, se constató que hablaban el escita. De aqui, los egipcios dedujeron que el idioma natural de los hombres era el escita. Acojamos con toda reserva esta conclusión y aun esta experiencia.

Sea lo que fuere, es casi necesaria la hipótesis de que el hombre ha variado desde un principio las entonaciones de su voz, según sus sensaciones, sus voliciones, sus necesidades. Ahora bien, a medida que sus sensaciones, sus voliciones y sus necesidades han aumentado en número. en complejidad y en intensidad. las entonaciones de las tonalidades que las expresan han seguido una marcha paralela. Dicho de otra manera, a medida que la inteligencia se ha desarrollado, las modalidades de la voz han debido aumentar al mismo tiempo.

Pero. por una justa compensación, a medida que los sonidos han llegado a ser más variados. la inteliģencia ha crecido a su vez, y muy rápidamente. Ha habido un encadenamiento reciproco, una admirable concatenación, un notable ciclismo. La inteligencia, al desarrollarse. ha creado el lenguaje. y. a su vez, el lenguaje. al hacerse articulado. matizado. ha hecho a la inteligencia más vasla y más precisa, de suerte que debe admitirse lo que más arriba dije: que la inteligencia ha creado el lenguaje y que el lenguaje ha fortificado. ampliado, desarrollado la inteligencia. El lenguaje es un producto de la inteligencia; pero la inteligencia es, a su turno, un producto del lenguaje.

Si existe tan profunda diferencia entre la inteligencia del hombre y la del animal, es porque el hombre ha logrado darse un lenguaje. Adquisición maravillosa. que ha traido consigo nuestro inmenso poder intelectual. generalización, abstracción. silogismo: ciencia, por lo tanto. y transmisión de esta ciencia a las generaciones siguientes. Reducido a sus sensaciones y a sus instintos, el hombre sería muy poca cosa. apenas superior a los grandes simios. No podría comunicar a sus semejantes sino una noción confusa de los sentimientos pasajeros que lo agitan, y sería incapaz, no sólo de transmitir su pensamiento, sino tal vez de tener un pensamiento. No es hombre. sino porque tiene un 
lenguaje. Que el lenguaje sea exterior o interior, no importa: siempre es la facultad de asociar las sensaciones presentes a las sensaciones pasadas, generalizando unas y otras.

Más lejos demostraré que. sin duda, las diferentes mentalidades de los hombres se deben a sus diferencias de lenguaje. Con razón, pues, se habla de tal o cual civilización, agregándole el epiteto lingüístico a que esta civilización se aproxima. Pero, antes de abordar este problema, quiero examinar lo que llegaria a ser nuestra inteligencia si no tuviéramos el lenguaje para servir de sostén a nuestras ideas.

\section{III}

Seguramente, podriamos sentir las emociones que experimentan los animales: el hambre, el frio, el dolor. la cólera, el amor, la alegria. Podríamos aún hacer conocer estos movimientos interiores del alma por las entonaciones de nuestra voz. Pero no iriamos más allá. Máquinas sensibles, lo concedo; pero máquinas incapaces de generalizar, de razonar; por consiguiente, de pensar verdaderamente: pues cualquiera generalización no puede presentársenos sino en una forma verbal.

Tomemos una idea abstracta, pero simple; la idea de patria. por ejemplo. ¿Es posible tener el concepto de patria si no to expresamos por una palabra? Es menester una palabra. un signo verbal, para concentrar las múltiples imágenes que entraña la idea de patria. Nuestras sensaciones no son sino emociones. afectivas o repulsivas. dolorosas o agradables. que provocan estados de conciencia diversos, pero que nada tienen de ideas ligadas entre sí.

¿Palabras, palabras, decía Hamlet, desdeñosamente. Pero es casi una blasfemia despreciar las palabras de tal suerte.

Las ideas de patria, de deber, de remordimiento, de justicia, de verdad, de ciencia, de bondad, son hasta tal punto complejas, que para sintetizarlas, hace falta un signo fonético (exlerior o interior).

La idea se confunde con la palabra. 
Suprimid las palabras abstractas patria, deber, verdad. justicia, y no quedarán sino imágenes concretas de objetos variados que no se únen uno a otro por ningún enlace lógico.

Por lo contrario. cuando decimos patria. inmediatamente se forma en nuestro espiritu una sintesis. Desde que, mentalmente - prácticamente, se presenta la palabra, en el acto aparecen múltiples imágenes: la bandera (simbolo). el ejército (simbolo). el gobierno (simbolo). la historia de nuestros abuelos (simbolo). el suelo natal (simbolo). la lengua que hablan nuestros compatriotas (simbolo también). Todos estos recuerdos, todas estas concepciones, se sintetizan en una sola palabra. y si no cuento con esta palabra que reune todos esos elementos dispersos. no tendré nada más que imágenes incoherentes.

Cuando Hamlet habla de las palabras con desprecio. es que ve una oposición entre el hombre que habla y el hombre que actúa. Pero no se actúa sino porque se ha pensado. Actuar. a menos de ser bruto. es actuar después de haber reflexionado. La accción, en el sentido noble que damos a esta palabra. no es un acto animal dirigido por sensaciones fugaces. es una acción determinada por recuerdos, impresiones, razonamientos. vibraciones. que sólo las palabras pueden dar.

Si no fuviéramos palabras y lenguaje para expresar los números, no lograriamos contar más que la gallina, que sólo puede numerar ocho de sus polluelos. Darwin dice que ciertos salvajes cuentan en esta forma: 1.2. 3, 4, mucho.

Lo que constituye la fuerza del pensamiento es el ser capaz de abstracción: ahora bien. no hay abstracción posible sin un signo verbal que haga accesible a la conciencia la idea abstracta.

Notemos, si, que este signo verbal que condiciona el pensamiento no tiene necesidad de aparecer en la forma de sonoridad exterior. Aun sin hablar, yo puedo tener las ideas de patria, de deber, de justicia, pues estos tres conceptos se fijan en mi espíritu gracias a su forma verbal. $M_{i}$ inteligencia seria del todo incapaz de formar estos conceptos si no tuviera, para concretarlos, un lenguaje, aunque sea interior; pues el lenguaje in- 
terior basta absolutamente a la inteligencia. de suerte que. cuando digo lenguaje. digo signo verbal que traduce una idea general y que se expresa o no por sonoridades exteriores.

En una palabra, sin verbo no hay pensamiento: no hay sino emociones.

\section{IV}

Para hacer más eficiente mi demostración, haré cuatro cilas prodigiosamente vulgares, pero que escojo a causa de su misma vulgaridad, para mostrar hasta qué punto es necesario el lenguaje para que una idea muy simple, accesible a todos los hombres. pueda ser desde luego concebida. en seguida expresada y por fin. comprendida.

1) Oderint dum metuant (que me odien. puesto que me temen):

2) El día no es más puro que el fondo de mi corazón:

3) El hombre no es sino una caña; pero una caña que piensa;

4) Todos tenemos bastante energia para sufrir los males de los demás.

He aqui cuatro frases célebres que todo colegial de quince años conoce o debe conocer. Son cuatro ideas, cuatro concepciones. Ahora bien, no veo cómo cualquiera de estas cuatro ideas pudiera haber nacido en la inteligencia, si no hubiera habido algún lenguaje para traducirla.

1) ¿Podría concebirse el confliclo entre el odio y el temor. si no tuviéramos estas dos ideas abstractas de odio y de temor ligadas entre si por la palabra dum (puesto que, con tal que): Puesto que me temen, ¿qué me importa el odio? Sin lenguaje, no podria pensarse nada semejante. Podemos, sin lenguaje, sentir aisladamente odio y temor; pero. para ligar uno a otro estos dos sentimientos, es necesario el lenguaje.

2) Cuando Racine dice: El dia no es más puro que el fondo de mi corazón. crea una imagen que sólo las palabras pueden expresar. ¿Cómo establecer sin palabras alguna com- 
paración entre la claridad de un día sereno y la inocencia de alma de Hipólito? Asimismo, parece que el hombre no puede concebir la inocencia de su alma. sino cuando dispone del lenguaje: porque la idea de inocencia es una idea abstracta.

$Y$, en cuanto a la comparación entre la hermosa luz del dia y la inocencia del alma, ésta ha menester un lenguaje, porque se trata de sentimientos que, aunque muy simples, son, no obstante, infinitamente más complicados que las emociones instintivas y animales, como desagrado. hambre. cólera. amor.

3) El hombre no es sino una caña: pero una caña que piensa. No intentemos ver si esta frase admirable podría expresarse en otra lorma que por medio de palabras. Es imposible. Tres ideas abstractas: el hombre, la caña (tomada como simbolo) y el pensamiento. Estas tres imágenes no pueden presentarse a nuestro espíritu, sino unidas por un lenguaje sabio.

4) La frase de La Rochefoucauld hace resaltar de una manera sorprendente el egoísmo de todo ser humano: requiere todo el poder de una lengua perfecta para ser concebida $y$ desenvuelta en todo su esplendor.

He tomado estas cuatro frases casi al azar. Podria tomar otras mil, para llegar a la misma conclusión, para saber que sin lenguaje, no hay pensamiento.

Tengo hambre... Estoy cansado... La nieve es fria... Hay. tal vez, una presa por ahi... Es inquietador ese ruido... Ha terminado el dia... Es preciso volver a la caverna... Mis hijos tienen hambre... Voy a buscarles alimento... Tal es. más o menos. el limitado circulo de concepciones que pueden formarse los seres privados de lenguaje.

\section{V}

Dara una ciencia cualquiera, aunque sea elemental, hace falta un lenguaje. En efecto, la ciencia es siempre la transformación de un hecho particular en un hecho más general, la cohesión de estos hechos generales ligados por una ley. Dicho de otra 
manera, la ciencia es una generalización, y no es posible generalización alguna sin lenguaje.

Sé muy bien que, ayudado de su memoria, un perro que caza en el campo reconoce por el olfato que tiene ante él una perdiz, una liebre o una codorniz. Sé también que un asno y un caballo reconocen los caminos que han frecuentado. Pero estas no son sino asociaciones de sensaciones presentes con recuerdos pasados; no hay aqui la menor abstracción; por lo tanto. ningún embrión de ciencia.

Sin lenguaje, no hay lugar posible para la aritmética, aun para la más rudimentaria: con mayor razón. para las matemáticas superiores. El álgebra, al crear una lengua nueva, ha extendido enormemente los dominios del pensamiento. Aun más. esta lengua nueva, verdaderamente internacional, ha llegado a ser tan frondosa. tan rica en abstracciones y en símbolos, que muy pronto llegó a ser absolutamente ininteligible para el vulgo. Ciertas páginas de los. Informes de la Academia de Ciencias están escritas en una- lengua simbólica, tan abstracta. tan profundamente complicada, que sólo un pequeño número de iniciados puede entenderla. Pienso que ciertas páginas de Enrique Poincaré o de Einstein no son comprendidas sino por una cincuentena de personas esparcidas por el mundo. iY es mucho!

Las otras ciencias no son menos exigentes en materia de expresiones verbales.

¿Podria existir la química. si no tuviera algún vocablo bien determinado para expresar la existencia de cuerpos simples? ¿Qué concepto nos formaríamos del oxígeno si estuviéramos reducidos a nuestras sensaciones? Es preciso un signo verbal para caracterizarlo. Ciertamente, para significar el dolor o el placer. el temor o la cólera, no es indispensable ninguna terminologia verbal; bastan las onomatopeyas. Pero cuando llegamos a una entidad química como el oxígeno, es necesario el verbo. Con mayor razón. si se trata de enlazar dos entidades quimicas una a otra, como. por ejemplo, la combinación del oxígeno con el hidrógeno. Esto es tan verdadero, que, para 


\section{El lenguaje y la inteligencia}

comprender bien su ciencia. los quimicos han debido crear un lenguaje especial que todo to simplifica. En vez de decir; el oxigeno se combina con el hidrógeno para formar el agua. escriben:

\section{$2 \mathrm{H}+\mathrm{O}=\mathrm{H}^{2} \mathrm{O}$}

Esta simbolización hace inmediatamente más claro y profundo el sentido de la combinación de estos dos gases.

La física, más abstracta aún que la química, no puede ser abordada sino por el lenguaje. No es dudoso que los salvajes conozcan el rayo y sus efectos, que tiemblen a la espera del trueno: pero de aquí a concebir la fuerza eléctrica, hay larga distancia. Aunque un grito especial para indicar que el rayo acaba de caer. usasen habitualmente. esto no les enseñaría nada acerca de la fuerza eléctrica. ¿Cómo hacer comprender. sin lenguaje. que la electricidad y la luz son vibraciones del éfer?

Los fenómenos cósmicos que nos rodean. sea la claridad del sol. o la caida de las piedras, o el crecimiento de los árboles. - las oscilaciones de las mareas. se presentan a los seres terrestres en la forma de hechos aislados cuya unión escapa totalmente cuando no hay un lenguaje para establecerla. Toda la fisica moderna. expresada por las palabras: atracción. electricidad. elasticidad, vibración. disociación, yonización. cohesión. etc. no existe sino gracias a la simbolización verbal.

En medicina. en fisiologia, en bacteriologia. no es menor la necesidad de las palabras. ¿Cómo. por ejemplo. expresar de otra manera que por una palabra la célula microscópica, microbio. que es probablemente el origen de todas las enfermedades? Nucstra vista no nos la revela si "no empleamos el microscopio, y se requiere la palabra para darle toda su generalidad.

Pero no queremos prolongar esta enumeración. Tan necesario es el lenguaje a la ciencia. que con cierta razón ha podido sostenerse que la ciencia no es sino una lengua bien he- 
cha. Deciamos precedentemente que no hay pensamiento sin lenguaje. Con mayor razón debemos decir que no habría ni la más pequeña traza de ciencia sin lenguaje.

\section{VI}

Se objetará, tal vez, que hay ciertas enfermedades en que la inteligencia persiste, en tanto que la función tenguaje se halla prolundamente turbada, y aun, a veces, completamente abolida. Con una lesión de la tercera circunvolución frontal del cerebro izquierdo. se produce la abolición de la palabra. Ahora bien, se pretende que la inteligencia permanece intacta.

Habría serias reservas que hacer acerca de la llamada integridad intelectual de los afásicos. Su inteligencia se hace débil, infantil, y por lo menos parcialmente, se ha oscurecido.

Aun asi. aceptemos un momento la opinión común de que los afásicos permanecen inteligentes, que tienen ideas todavía, pero que les falta la palabra para traducirlas en sonidos. Sea. Pero. a pesar de todo. conservan todavia el lenguaje interior. La afasia es motora, es decir. los medios de expresar vocalmente las ideas han sido turbados por la parálisis, pero. gracias al lenguaje interior, la idea persiste, puesto que el signo verbal interior no ha sido abolido.

Supongamos, por ejemplo, un individuo áfono porque padece una parálisis complefa de la laringe. Evidentemente. por este hecho, nada habrá cambiado en su constitución mental.

Supongamos aún que la lesión sea más profunda y que este individuo áfono. convertido en afásico. no puede ya articular palabras con los labios: habrá conservado el lenguaje inlerior, y ya es bastante para el ejercicio de la inteligencia.

Luego, sobre todo, aun cuando la función del lenguaje se halle abolida por la hemorragia cerebral, el desgraciado afásico habrá sido normal durante todo el curso de su vida anterior. y. por lo tanto, habrá podido adquirir. como los demás hombres. y gracias al lenguaje. potencias intelectuales que no permitirán que llegue a ser tan impotente mentalmente como lo 
hubiera sido si jamás supiera del signo verbal para dar cuerpo a sus ideas.

Sin duda, los sordo-mudos mismos no están desprovisios de lenguaje interior, puesto que pueden aprender a leer. a escribir. y aun, a veces, a hablar un poco. El elemento fundamental del lenguaje, es decir, el empleo de un signo verbal para una idea abstracta, no está abolido.

$\mathrm{Ni}$ los afásicos, ni los sordo-mudos, puesto que conservan un lenguaje interior. están privados totalmente del poder de sinletizar las ideas por medio de palabras. Pero si suponemos una humanidad desprovista de este poder. ésta no será ya una humanidad: el hombre no seria más inteligente que el mono. el perro o el elefante

Se dirá, acaso. que hombres de una inteligencia hermosa e inventiva hablan muy mal y escriben fan mal como hablan. Pero. si en ellos es defectuoso el lenguaje exterior. tienen seguramente un lenguaje interior muy elocuente: pues no podrian tener alguna precisión en su ideación. si la idea no se concretara en la palabra justa.

No podemos pensar sin traducir inmediatamente nuestro pensamiento en palabras. Aun cuando nos entregamos al sueño. fatalmente este sueño brumoso se condensa en palabras. No podría imaginar un árbol sin que repentinamente la palabra árbol brillara en mi espiritu; $y$. si no es la palabra árbol. es tal - cual árbol especifico. encina. fresno. álamo. cerezo. Pero siempre es en una forma verbal como aparece la idea. No puedo agregar un atributo cualquiera a un objeto. sin que esté atributo sea verbal. tanto como el objeto. No podemos pensar sin la ayuda de las palabras.

Algunas veces, ciertamente, buscamos la palabra que exprese nuestro pensamiento, y no la hallamos inmediatamente. iY bien!. si la buscamos, es que la conocemos. Sabemos que existe. y porque conocemos su existencia, tenemos de ella una idea inconsciente. Está escondida en las profundidades de nuestra memoria, y sabemos que llegaremos a encontrarla. En efecto. lodo lo que está en nuestro lenguaje interior no está presente inme- 
diatamente en nuestra conciencia. A menudo se requiere un esfuerzo, a veces infructuoso, para encontrarlo.

Hay más. Para muchos poetas, por ejemplo. la rima, es decir. la palabra, evoca una imagen. o sea, una idea nueva. Me atrevería a decir que a menudo la palabra precede a la idea. En todo caso. hay simultaneidad entre la idea y la palabra. Aparece en el espíritu una idea que se traduce inmediatamente por una expresión verbal vecina (Ionéticamente) a la primera: dicho de ofra manera, aparece la rima, que despierta otra imagen.

Para que el pensamiento no sea indeterminado, incierto, flolante en una bruma oscura, análogo a la tosca sensibilidad de los animales privados de lenguaje, son necesarios los signos verbales, que tienen la doble virtud, en apariencia contradictoria. de precisar y de generalizar.

\section{VII}

Puesto que el desarrollo intelectual sigue al desarrollo del lenguaje. convendría investigar aqui en qué consiste la perfección de una lengua.

Existen, como se sabe. la gramática y el vocabulario.

Dejo de mano inmediatamente las cuestiones gramaticales. Aunque logren regir a los mismos reyes. las gramáticas no tienen tal vez otra importancia que la de fatigar inútilmente el espiritu de los niños.

Entiéndase. sí, que la corrección gramatical es tan necesaria como la corrección ortográfica, tan imperativa como la corrección de los vestidos y de los ademanes: es un minimum indispensable. Por lo demás, cuanto más simples sean las gramáticas. tanto mayor valor tendrán. Las complicaciones y, como se dice a veces, el preciosismo de la gramática, son execrables.

Pero, en el fondo, esto importa muy poco. porque lo que da a una lengua su verdadero carácter, es su vocabulario. Un vocabulario rico y. al mismo tiempo. exacto, con términos capaces de dar los más delicados matices de un pensamiento sutil. sin que haya en él incertidumbre acerca del sentido profundo 
de las cosas, tal es to que debe desearse. Como dijo un escritor maestro, en una lengua perfecta no hay sinónimos, y no puede reemplazarse impunemente una palabra por otra. Todo cambio de un término verbal lleva consigo algún cambio de la idea, aunque se trate de palabras muy cercanas.

Ninguna lengua ha llegado repentinamente a su perfección: ha sido necesario un largo uso. Pulida, elaborada, codificada, matizada por nuestros grandes escritores. la lengua francesa ha terminado por adquirir, al fin de cuatro siglos, esta riqueza, esta claridad, esta precisión en los menores términos, me atrevería a decir esta modulación de matices, que hace de ella un maravilloso instrumento de pensamiento.

De mala manera logramos darnos cuenta de la influencia preponderante que la forma del lenguaje ejerce sobre la forma del espíritu. El lenguaje dirige inconscientemente nuestra mentalidad. pues es el elemento esencial del pensamiento. Gracias a nuestra lengua, el pensamiento francés tiene un carácter especial. y es esta especiatización lo que hace que nuestra nacionalidad sea lo que es y difiera de las demás nacionalidades.

La propiedad de los términos exactamente adecuados a tal o cual idea, una construcción lógica y metódica, el juicioso cmpleo de las más pequeñas preposiciones, hacen que la lengua francesa sea de una claridad superior. claridad que se refleja en las obras, prosa o poesía, de los grandes escritores.

Si llamamos nación a Francia, es porque, gracias a este común y maravilloso instrumento de nuestra lengua, todos tenemos. más o menos, una forma particular en nuestra ideación.

$¿ Q u e ́$ consideraremos. en efecto. para caracterizar una nacionalidad? La historia nos enseña que las fronteras de los Estados son variables. $Y$. en cuanto al punto de vista etnográfico, en diez siglos los europeos se han mezclado de tal suerte. que ya no exisle, fisiológicamente, la raza francesa más que la raza alemana o la raza italiana. En nuestro noble suelo francés, las invasiones sucesivas mezclaron los celtas con auverneses. los romanos con los cimbrios. los francos con burgundas. Los iberos. los godos, los normandos, se han entrelazado de tal suerte 
los unos a los otros. que ya no hay carácter étnico especial.

Pero hay un carácter mental de nuestra nacionalidad debido. por una parte. me place creerlo, al suelo, al clima, a la historia: pero debido. sobre todo. a la lengua común que hablamos. Asimismo, no puedo resistirme a considerar en algo como compatriotas mios a las gentes de Ginebra. de Bruselas. de la Isla Mauricio, de Quebec; porque la lengua francesa es su habla nacional.

Esta lengua francesa misma. por su vocabulario. es una lengua por de pronto latina. como el italiano. como el español. Tenemos, pues, el derecho de hablar de una civilización latina: pues, por su origen común, estas tres lenguas. tan parecidas. son verdaderamente hermanas. $Y$ esta similitud establece inmediatamente una marcada analogía en la psicología profunda de estos tres grandes pueblos.

No quiero introducir aqui, aunque sea superficialmente, una discusión sobre la cuestión tan controvertida en la actualidad. de la enseñanza del latín, y no trataré de entrar en la exposición de todas las razones. buenas o malas. que han sido alegadas a este propósito, por una y otra parte. Sin embargo, me parece que la comprensión perfecta de la lengua francesa se facilita singularmente por el conocimiento del latin. Tanto mejor hablaremos nuestra lengua. cuanto más hayamos frecuentado los grandes autores latinos. en el supuesto. por cierto, de que habremos frecuentado más asiduamente aún los grandes escritores franceses.

Seguramente, es fácil encontrar numerosos excelentes escritores franceses que no tenian sino imperfectas nociones de latin. pero éstos son las excepciones. Los maestros de la lengua francesa fueron casi siempre excelentes latinistas, de Rabelais a Montaigne, de Racine a Voltaire. de Chateaubriand a Victor Hugo, de Michelet a Renan y a Taine. 


\section{VIII}

Quiero probar por algunos ejemplos que es la lengua lo que crea, casi, el pensamiento.

En el hecho, los hombres,-europeos y occidentales.-que viven en la superficie del planeta con sus civilizaciones semejantes, con sus costumbres, no fundamentalmente diferentes, con una historia que se confunde. con una legislación que a veces se copia en sus más pequeños detalles. tienen, más o menos. las mismas ideas esenciales. simples y uniformes. Si queremos despojar de su estilo incisivo los más grandes pensamientos de los mejores escritores, quedaremos admirados al ver hasta qué punto son vulgares. Nada puede demostrar más claramente la influencia del lenguaje sobre la idea, que el análisis de ciertas vulgaridades que han llegado a ser grandes pensamientos. porque un lenguaje admirable ha sabido transformarlos y vivificarlos.

Gracias a un epiteto feliz, a una imagen atrayente, a una metáfora audaz, una pobre vulgaridad se presenta como clocuente y nueva. Las vulgaridades más vulgares. los lugares comunes más comunes, toman. gracias al lenguaje. dicho de otra manera, gracias al estilo, un sabor especialisimo. Por el brillo de una imagen imprevista. la vieja verdad se convierte en idea original; estaba débil y gastada: se hace poderosa y rara.

$\mathrm{Y}$ aquí, aún. citaré algunos ejemplos.

¿Qué hay de más terriblemente vulgar que la triste, miserable condición de los hombres. la necesidad ineluclable del dolor? Pero La Bruyère escribe: Apresuraos a reir antes que a ser felices. por el temor de morir sin haber reido. entonces, repentinamente. toda vulgaridad se desvanece. Imágenes, ideas nuevas. múltiples. frondosas, vivientes. se injertan en la idea madre. dándole un vigor inesperado. La oposición entre la risa y la alegría, entre nuestras aspiraciones y la fragilidad de la mezquina vida humana, todas ideas virtualmente incluidas en la vulgar idea primiti- 
va, brilla luminosa y potentemente. gracias al brillo y a la potencia del lenguaje.

No conocemos los límites del espacio; estamos rodeados de extensiones que no tienen fin. Nada más ordinario que esta concepción del espacio. Todos los hombres, aun los más ignaros, la piensan y posiblemente la dicen. Pero he aquí que repentinamente se abren perspectivas profundas. Pascal ha hablado. Ha dicho (probablemente después de otros): iEl mundo es una esfera infinita cuyo centro está en todas partes y cuya circunferencia, en ninguna!

Uno de mis más queridos amigos. arrebatado temprano a la poesia. Emilio Guiard, expresaba una idea muy corriente: los campesinos llevan una vida estrecha; y halla versos armoniosos y profundos que enriquecen esta vulgaridad, de tal suerte, que llega a ser fecunda en hermosas imágenes:

Le laboureur, courbé sur sa lente charrue.

Au delã de son champ ne porte pas sa vue.

Il croil qu'il lui suffit de voir son blé mûrir

Et que c'est vivre assez que de ne pas mourir.

Nul bonheur au dehors n'excite son envie:

II sème dans son champ tout l'espoir de sa vie.

Il pense, à son enclos bornant son horizon.

Que le monde finit où finit sa maison.

No hay quien no conozca la admirable poesía de Victor Hugo, la Tristesse d'Olympio. Pues bien. loda esta pieza, una de las obras maestras de la poesia francesa. no es sino la paráfrasis de una idea ingenua, vulgar. tan antigua acaso como el hombre: que nuestra vida es breve y que el mundo continuará su camino después de nosotros. sin cuidarse de nuestro destino: pero, iqué imágenes! iqué aladas palabras! iqué armonia! iqué sonoridades! iqué renovación de esta añejez! icuánta majestad en esta antigua angustia! 
Que peu de temps suffit pour changer toutes choses!

Nature au front serein. comme vous oubliez.

Et comme vous brisez dans vous métamorphoses

Le fils mystérieux où nos coe-urs sont liés!

D'autres vont maintenant passer où nous passâmes

Nous y sommes venus, d'autres y vont venir.

Et le songe quavaient ébauché nos deux âmes

Ils le continueront sans pouvoir le finir....

Me detengo... Seria menester citarlo todo. Es como una lluvia de estrellas relumbradoras. que brillaria con humilde desteIlo: la idea matriz es harto pobre; pero. mediante el estilo. se hace sublime.

Podría coger fácilmente innumerables ejemplos para establecer que. cuando no se trata de un descubrimiento cientifico, hay, al fin de cuentas. muy pocas ideas nuevas en los cerebros humanos.

Todo está dicho, y siempre llegamos demasiado tarde.

Si, todo está dicho. Pero la manera de decir no es, si. siempre la misma. La forma hace valer el fondo. Las concepciones fundamentales son idénticas para todos nosotros. Jóvenes o viejos. grandes o pequeños. germanos. franceses, anglo-sajones. árabes, no pensamos sino cosas limitadas y simples; de tal suerte que la diferencia esencial entre un hombre infeligente $y$ un hombre mediano. es la manera de expresar sus ideas. Lo que hace que un gran escritor no sea un vaquero inculto. es el que aquél sepa verbalizar su pensamiento en términos nuevos. imaginativos, netos, vivos. Cada palabra que introduce en su frase hace novedosa la más llana de las ideas. Sobre un terreno uniforme, lanientablemente uniforme. germinan las plantas o. si se quiere, las palabras cuya forma, vigor y destello varian hasta lo' infinito.

Es el lenguaje. más que las ideas, lo que diferencia a los hombres. Es el lenguaje lo que crea el pensamiento.

Expresado de diversa manera. lo que caracteriza a los grandes pensadores y a los grandes escritores, es la riqueza y la 
precisión de su vocabulario: pero de ninguna manera la prolundidad de su ideación.

Sería curioso trabajo,-curioso e ingrato a la par - poner en lenguaje vulgar las observaciones profundas que provocan nuestro entusiasmo en los maestros. Quedariamos estupefactos al ver hasta qué punto puede transformarse finalmente lo que ellos dicen, en una idea lastimosamente ordinaria.

Si quitamos las imágenes y rebajamos el estilo. loda profundidad desaparece.

\section{IX}

De tal suerte, la verdadera originalidad de los hombres se debe a su lenguaje, puesto que todos tienen, poco más o menos. las mismas concepciones y el fondo es uniforme. cuando menos para los europeos, nuestros contemporáneos. Se sigue de aquí, necesariamente, que la perfección de una lengua lleva consigo una inteligencia más firme, más extensa, más clara, sobre lodo. Desgraciadamente carezco de competencia para deducir un juicio de otra lengua que no sea la mía. aunque esté en condiciones de leer corrientemente ( $\sin$ poder en lo más mínimo expresarme en estas lenguas) el inglés. el italiano, el alemán. Aun así. me atrevo a pensar que la lengua francesa, con su concisión. su lucidez, su fineza, es el más maravilloso instrumento de la inteligencia humana (:).

Entendámonos bien acerca de esta palabra instrumento. La lengua no es sólo un instrumento manejado por la inteligencia: es un instrumento creador: ayuda al desarrollo intelectual. tanto en las ciencias como en la literatura. En efecto, por una parte.

(*) Tal es fambién la opinión de muchos extranjeros. No me cansaria de aconsejar a los amantes de la lengua francesa leer un libro admirable que acaba de escribir un americano: El francés, lengua diplomática moderna, por James Brown Scott, profesor de la Universidad de George Town (un vol. in-8.0 de 328 págs.. Paris. Pedone, 1924). Este libro, precedido de una hermosa introducción de M. Nicholas Murray Butler. el sabio presidente de la University Columbia de Nueva York, es una apologia crítica y prolundizada de nuestra querida lengua francesa. El problema histórico está frafado con tantos defalles, que esfe hermoso libro podria fifularse: El pasado. el presente y el porvenir de la lengua francesa en el mundo. La conclusión del profesor James Brown Scoff es que, en la hora actual, el francés es la primera de las lenguas. 
el desarrollo de las ciencias y del lenguaje se cumple paralelamente; el lenguaje llega a ser cada vez más rico a medida que la ciencia se enriquece, y esta riqueza creciente del lenguaje presta su impulso a la ciencia. Por otra parte. en cuanto a la literatura, cuantas más palabras tiene para expresar los matices de una idea, tanto más la idea, vulgar al principio. llega a ser penetrante.

Aquí es donde quiero llegar. Cuando se habla de una civilización francesa, implícitamente se habla de una civilización que se debe a la lengua francesa.

Así, pues, con un cuidado celoso debemos mantener nuestra lengua en toda su sobria pureza, y, conservándole su forma actual, enriquecerla aún con nuevas adquisiciones, pero siempre con una prudente reserva; los maestros nos han enseñado qué alto grado de perfección puede dar a la idea el habla francesa.

$Y$ ya que hablo de civilización. que, para lerminar, me sea permitido esperar ( $y$ aun afirmar) que la civilización llamada latina, aunque amenazada en su expansión por civilizaciones rivales, no sólo no perecerá, sino que seguirá creciendo. A decir verdad, la lengua inglesa está mucho más próxima a la lengua latina de lo que ordinariamente se cree; las lenguas germánicas se apartan un poco más del latin; las lenguas eslavas se apartan mucho más todavía: con mayor razón la lengua de los árabes; con razón más señalada aún, la de los chinos. cuya escritura barroca exige muchos años de largos estudios para ser trazada con corrección.

Resumiendo, debe considerarse la mentalidad humana ligada en conjunto a la forma del lenguaje. Toma de éste tanto las virtudes como los defectos.

Por tanto, si fuera menester dar una conclusión práctica a este análisis, tal vez un poco abstracto. me parece que podría resumirsela en una frase muy corta: . Cuidemos nuestra lengua francesa, porque ella es lo que de nosotros ha hecho franceses.

CARLOS RICHET.

(Trad. para Atenea, de Revue des Deux Mondes, 1.0 de Febrero de 1925). 